\title{
МЕТОДОЛОГИЧЕСКИЕ ПОДХОДЫ К ИССЛЕДОВАНИЮ ПСИХОЛОГИЧЕСКОГО БЛАГОПОЛУЧИЯ РОССИЙСКИХ И АРМЯНСКИХ СТУДЕНТОВ
}

Исследование выполнено при финансовой поддержке РФФИ и КН РА «проект № 20-513-05005 20 »

Самохвалова А.Г. (Костромской государственный университет, Кострома, Россия), Асриян Э.В. (Ереванский государственный университет, Ереван, Армения) a_samohvalova@ksu.edu.ru; elina.asriyan@gmail.com

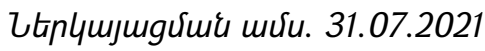

9pupunuर्ume uर्u. 24.08.2021

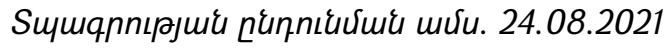

В статье поднимается актуальная проблема исследования психологического благополучия студентов. Представлено авторское понимание феноменов «благополучие», «психологическое благополучие» и «субъективное благополучие» личности. Психологическое благополучие определяется как интегральная характеристика состояний субъекта, обеспечивающих согласованность всех психических функций и процессов, достижение внутреннего равновесия и субъектной целостности. Обоснованы методологические подходы к организации кросскультурного исследования психологического благополучия студентов, обучающихся в вузах России и Армении. В качестве важнейших подходов определены социокультурный, рассматривающий развитие студента в контексте его взаимодействия со средой, предполагающий изучение влияния на уровень психологического благополучия ближайшего социального окружения (особенности образовательной среды, семейного климата, социального капитала), и других макро-факторов (этнос, национальные традиции, идеология, ценности, социально-экономический уклад жизни); а также контекстный подход, позволяющий рассматривать ситуацию очного обучения в вузе в качестве предиктора психологического благополучия российских и армянских студентов, с учетом иных контекстов жизни (проживание в семье или отдельно от родителей, проживание в родном городе или переезд в другой город, «академический» вариант обучения или совмещение учебы с работой).

Ключевые слова: благополучие, психологчческое благополучие, субъективное благополучие, студенты, сочиокультурный подход, контекстный подход. 
DOI: https://doi.org/10.46991/SBMP/2021.4.2.292

Современная социокультурная ситуация развития общества характеризуется интенсивностью трансформационных процессов, которые, в свою очередь, приводят к повышению стрессогенности социальной среды и усилению социальной напряженности. В условиях возрастания техно-, био-, социогенных угроз и рисков на первый план выходят вопросы, связанные с сохранением психического здоровья и обеспечением психологического благополучия индивидуального и группового субъекта жизнедеятельности. При этом залогом динамично развивающегося, сензитивного, адекватно реагирующего на вызовы времени, совладающего с ними общества является психологическое благополучие молодежи как страты, от которой зависит будущее любого государства.

На данный момент мы наблюдаем тревожную картину в современном мировом сообществе. Значимая часть студенческой молодежи склонна к аддиктивному, деструктивному (в том числе суицидальному) поведению, проявляют тревожность и депрессивность, испытывает трудности конструктивного совладания с жизненными трудностями и самопроектирования. Это во многом связано с тем, что отражение высокой степени неопределенности будущего, вовлеченность в жесткую стратификационную конкуренцию, агрессивную, насыщенную информационную среду, параллельное функционирование в реальном и виртуальном пространствах и, при этом, необходимость решать возрастные задачи требуют от молодежи высокой степени психологической устойчивости, адаптивности, ресурсности.

Наши исследования, посвященные проблеме самоэффрективности студентов (2015-2020 гг.), показывают, что более трети молодых людей низко оценивают собственную успешность в жизни, в том числе и академическую. Они закрыты, испытывают серьезные трудности в установлении и поддержании контактов, ориентированы на поощрение, внешнюю стимуляцию, имеют низкую самооценку, склонны к самообвинению. При решении собственных проблем отдают предпочтение избеганию и уходу от них. У них ярко выражены защитные барьеры в осмыслении своего актуального опыта. Поиск смысла жизни, характерный для данной возрастной группы, затрудняется, что связано с расщеплением культурного ядра, утратой самобытности, отсутствием ярко выраженных нравственных, ценностных ориентиров в современном мире. Возникающее ощущение пустоты, бессмысленности существования, подмены ценностей, в свою очередь, прямо отражается на психологическом благополучии молодого человека, снижает его жизнестойкость, адаптивность, лишает его внутреннего равновесия и ощущения целостности. Осознание необходимости изучения психологического благополучия личности, отдельных социальных групп и общества в целом стимулировало интенсивное развитие 
данного научного направления в последние десятилетия. Общепринятый смысл феномена благополучия сводится к определению, данному в словарях русского языка, - это удача, благосостояние; спокойное и счастливое состояние человека; обычное, без отклонений от нормы или нежелательных явлений состояние кого-либо [1].

В современном научном дискурсе можно выделить различные научные подходы к пониманию понятия "благополучие», которые, в целом, не являются взаимоисключающими [3]:

- объективные списки, которыеявляются перечнем потребностейили условий, которые способствуют благополучию;

- удовлетворение предпочтений,предполагающий, что люди делают рациональный выбор и используют свои ресурсы для удовлетворения своихжеланий и предпочтений;

- оценочный подход, основанныйна оценке людей того, насколько хорошо они живут («субъективное благополучие», subjectivewell-being (SWB));

- гедонистический подход, фокусирующий свое внимание на субъективном ощущении счастья, возможности получать удовольствие от жизни.

- эвдемонистический подход, делает акцент на процессах самоактуализации, саморазвития и «витальности» личности, т.е. наполненности жизненной энергией; в рамках данного подхода психологическое благополучие представлено шестью аспектами человеческого потенциала: автономия, личностный рост, самопринятие, жизненная цель, мастерство и позитивное отношение к жизни [14].

При этом научные исследования преимущественно сосредоточены в области изучения психологического благополучия личности (Н.К. Бахарева, М.В. Бучатская, А.В. Воронина, А.Е. Созонтов, П.П. Фесенко, Т.Д. Шевеленкова, Я.И. Павлоцкая). На данный момент нашли отражение в науке вопросы изучения структуры психологического благополучия личности, разработаны отечественные и адаптированы зарубежные методики, позволяющие измерить уровень психологического благополучия личности (Л.В. Жуковская, Е.Г. Трошихина, Л.В. Куликов), рассмотрена возрастная и половая специфика в переживании психологического благополучия (А.В. Воронина, Бучацкая М.В., О.Б. Подобина, Д.М. Зиновьева, Ю.Б. Дубовик), проанализирована связь психологического благополучия с сопряженными феноменами, а именно, самоактуализацией (С.П. Пучкова), осмысленностью жизни (П.П. Фесенко), социальной активностью (Р.М. Шамионов), совладающим поведением (Т.Л. Крюкова). Появляются и исследования как ответ вызовам современности, к примеру, посвященные особенностям психологического благополучия людей в условиях чрезвычайных ситуаций, в том числе переживающих террористическую угрозу (Н.В. Тарабрина, Ю.В. Быховец, Н.Н. 
Казымова, О.С. Ширяева). Продолжаются теоретические разработки по классификации подходов к определению психологического благополучия личности (А.Е. Созонтов, Р.М. Шамионов), предложена модель исследования и формирования психологического благополучия (О.А. Идобаева).

Однако в науке до сих пор не достаточно четко дифрференцированы понятия «благополучие», «психологическое благополучие» и «субъективное благополучие». Осознавая сходство данных категорий, мы попытались дифрференцировать эти понятия.

Базовой установкой послужило то, что человек одномоментно существует в двух реальностях: объективной, где он реализует себя в социальном контексте как субъект общения, отношений и деятельности, и субъективной, которая является продуктом осмысления и переживания собственного бытия. Эти две реальности, вступая в сложные взаимосвязи и взаимовлияния, обусловливают общее благополучие субъекта, которое актуализируется в трех стратах:

- первая страта - благополучие субъекта, которое представлено в объективной реальности, его можно определить и оценить по критериям, существующим в определенной культуре (материальное, социальное, семейное благополучие, состояние здоровья, профессиональное развитие, карьерный рост, социальная активность);

- вторая страта - психологическое благополучие субъекта как интегральная характеристика состояний человека, обеспечивающих согласованность психических функций и процессов, достижение внутреннего равновесия и субъектной целостности; оно реализуется на психофизиологическом, индивидуально-психологическом и социально-психологическом уровнях;

- третья страта - субъективное благополучие как осознаваемая часть психологического благополучия, как образ собственной жизни и своего места в ней, который представлен лишь самому субъекту и является продуктом его рефлексии.

На наш взгляд, чрезвычайно важно рассматривать психологическое благополучие не только как объективную, но и как субъективную реальность, существующую в сознании человека, как обобщенный показатель степени направленности человека на реализацию целей и личностный рост, управление средой и формирование доброжелательных отношений с окружающими, самопринятие и автономию. Уровень реализации этих устремлений находит свое выражение в счастье, удовлетворенности своей жизнью и собой [12, с. 103].

Понимание благополучия как субъективной реальности в виде психического состояния говорит о том, что это явление имеет начало и конец, оно подчиняется временным закономерностям и обладает длительностью, дискретностью, необратимостью и т. д. [1, с. 78]. Именно поэтому психологическое благополучие необходимо изучать в динамике, анализируя изменения 
психических состояний субъекта. А.О. Прохоров рассматривает психическое состояние как отражение личностью социальной ситуации в виде целостного синдрома в континууме времени, при этом основной функцией состояния является уравновешивание, сохранение равновесия и необходимого взаимодействия внутреннего мира человека (субъективной реальности) с изменяющейся внешней средой [10]. И если рассматривать благополучие личности как изменяющееся образование, то при неравновесном состоянии можно говорить о неблагополучии личности, вызванном как внешними факторами (конфрликты, утраты, тяжелые заболевания и т. п.), так и внутриличностными детерминантами (борьба мотивов, утери ценностных ориентиров и т. п.) [9]. Bce это дает основание полагать, что, во-первых, важнейшим маркером психологического благополучия является гармония внутреннего мира субъекта с окружающей действительностью, а также его внутриличностная гармония; вовторых, изучение психологического благополучия / неблагополучия вне контекста ситуации, которой оно вызвано, малопродуктивно.

Следовательно, методологическую основу изучения психологического благополучия студентов должны, на наш взгляд, составлять социокультурный и контекстный подходы, позволяющие анализировать как общие, универсальные, так и специфические, связанные с социокультурным контекстом страны проживания, детерминанты и закономерности. В научном дискурсе на сегодняшний день существуют явные противоречия между наличием отдельных эмпирических исследований, направленных на выявление структурных компонентов и предикторов психологического благополучия личности, и отсутствием в данном проблемном поле комплексных исследований, позволяющих систематизировать и интегрировать разрозненные эмпирические данные, включив их в фундаментальный культурно-экологический контекст, связывающий субъекта и социальную среду; а также между де-контекстуализацией изучения составляющих психологического благополучия личности и необходимостью учитывать социокультурный и кросскультурный контексты для понимания и интерпретации эмпирических результатов.

Социокультурный подход в психологии базируется на методологии системного подхода, поскольку рассматривает общество как единство культуры и социальности, образуемых и преобразуемых деятельностью человека. Исследовать культуру необходимо как целостность, как систему, состоящую из множества согласованных, внутренне связных частей. Т. Парсонс акцентировал внимание на целостности общества как социетальной системы, включающей культуру. В процессе взаимодействия с обществом и выполнения своей человекотворческой миссии культура, в его понимании, предстает в трех своих взаимосвязанных аспектах. Во-первых, культура передается, она составляет наследство или социальную традицию; во-вторых, это то, чему 
обучаются, культура не является проявлением генетической природы человека, и, в-третьих, она является общепринятой. Таким образом, она, с одной стороны, является продуктом, а с другой стороны - детерминантой системы человеческого социального взаимодействия [8].

Культура в понимании Г.К. Триандиса есть высоко сложная, постоянно меняющаяся система значений (смыслов), разделяемая, передаваемая и изменяемая от поколения к поколению; это система общих установок, верований, классификаций, норм, ролей, ценностей, которые «организованы вокруг одной идеи». А.С. Ахиезер полагает, что культура - это программа деятельности субъекта. В повседневной жизни люди действуют В соответствии с исторически сложившимся содержанием культуры [11]. Социокультурный подход в науке конкретизируется в виде нескольких принципов: принцип человека активного («homo activus»), принцип взаимопроникновения культуры и социальности, принцип антропосоциетального соответствия, принцип социокультурного баланса, принцип симметрии и взаимообратимости социетальных процессов, принцип необратимости эволюции социокультурной системы как целого [5]. Следовательно, опираясь на эти принципы, можно представить ту или иную нацию, страну, социальную группу (например, студенческое сообщество) как большую самодостаточную социокультурную систему, возникающую и изменяющуюся в результате действий и взаимодействий «homo activus»; еe функции и структуры обеспечивают балансируемое удовлетворение противоречивых потребностей, ценностей и интересов субъектов деятельности и общения, входящих в эту систему.

В психологии развития социокультурный (экологический) подход весьма часто используется для объяснения паттернов поведения людей разных возрастных категорий. Суть этого подхода к изучению онтогенеза состоит в междисциплинарном объяснении процессов социализации человека. Согласно концепции Ю. Бронфенбреннера, развитие - это динамический процесс, когда, с одной стороны, многоуровневая жизненная среда воздействует на растущего индивидуума и, с другой стороны, сам он активно переструктурирует ее [13]. Автор выделяет четыре уровня жизненной среды, которые, на наш взгляд, дают понимание основных предикторов психологического благополучия студентов: микроуровень жизненной среды, включающий взаимодействие субъекта с его ближайшим окружением, характерные занятия и социальные роли; мезоуровень, который образуется, когда формальные или неформальные связи возникают между двумя или более микросистемами (например, между семьей и вузом, семьей и группой сверстников); экзоуровень, охватывающий широкую социальную среду, непосредственно не связанную с опытом субъекта, но косвенно влияющую на уровень его благополучия (характер занятости и образования родителей, экономическая ситуация в стране, наличие 
собственного жилья, роль средств массовой информации); макроуровень, который образует культурный и исторический контекст ценностей, традиций, законов, который оказывает весьма существенное воздействие на все нижележащие уровни. Таким образом, для понимания корней психологического благополучия студентов требуется учитывать не только предсказуемые возрастные изменения, характерные для периодов юношества и молодости, но и уникальные для каждого поколения широкие социокультурные и исторические фракторы.

В.И. Панов, разрабатывая методологию экопсихологии развития, изучал влияние окружающей среды на обучение и развитие личности (физическое, психическое и социальное). Говоря об окружающей среде, он имеет в виду среду семейную, образовательную, пространственно-предметную, информационную, этнокультурную и т.д. Отмечается, что окружающая среда играет двоякую роль в онтогенезе. С одной стороны, она предоставляет (или не предоставляет) условия для успешного развития; с другой стороны, является фактором, оказывающим влияние на процесс развития [7]. В данном контексте становится важным изучение влияния социокультурной среды вуза, фракультета, микроклимата студенческой группы на уровень психологического благополучия студентов, а также выявление факторов снижения и механизмов повышения индекса психологического и субъективного благополучия личности в образовательной среде. Таким образом, очевидно, что исследование психологического благополучия студентов должно базироваться не только на социокультурном подходе, но и на контекстном подходе. В социальной психологии контекст рассматривается как фактор, влияющий на поведение человека в конкретной ситуации (Г.М. Андреева, Д. Бивин, Д. Джексон, Е. Лангер, А. Маслоу, В. Франкл и др.). В концепции контекстуального интеракционизма (Н. Смит) психологическое событие рассматривается как взаимодействие между субъектом и объектом в контексте, включенность в который должна снимать оппозицию «психика/среда». В зарубежной психологии существует направление - контекстуализм (Р.М. Лернер, Д. Мацумото, Дж. Капрара и Д. Сервон, Д. Форд и др.), базирующееся на идее об обусловленности психики социокультурным контекстом. Контекст при этом относится к числу основных измерений культуры, а контекстуализация - это культурный показатель: степень, в которой культуры поощряют различающееся поведение в соответствии со специфическими нормами и ценностями, правилами (контекстом) в тех сообществах, где поведение имеет место. Выделяются два muna контекста: в культурах высокого контекста поведение индивида, прежде всего, определяется контекстом; проявлениям, присущим самой личности, а не ситуации, не придается особого значения; такие культуры позволяют индивиду (и вынуждают его) вести себя, а также выражать мысли и 
чувства, соответствующие особенностям ситуации или среды, в которой он находится; в культурах низкого контекста особое значение приобретает стабильность и постоянство проявлений личности в различных контекстах независимо от внешних факторов [6].

Мы полагаем, что уровень психологического благополучия студентов связан не только с культурным контекстом, но и с социальным, и с психологическим. Сочиальный контекст является важным фрактором в развитии индивидуальности человека и психики в целом. Так, А. В. Либин рассматривает человеческое поведение как преимущественно социальный феномен, испытывающий влияние социокультурного контекста, который понимается как «устойчивый набор ценностей, стереотипных представлений, правил поведения, разделяемых большинством членов данного социального окружения».

Психологический контекст - это не столько некоторая статичная структура (окружение) некоего объекта, сколько особый психический «механизм» репрезентации, чьи функции заключаются в структурировании, а также обеспечении означенности и осмысленности всех когнитивных процессов человека за счет соотнесения данного воспринимаемого объекта с совокупностью других. Это некоторая функциональная система, объединяющая все другие психические процессы (восприятие, память, мышление, воображение) в целях обеспечения соотнесения одного фрагмента информации с другими. В.Г. Калашников обнаруживает функциональное сходство картины мира, в том числе в форме языковой картины мира, и психологического контекста [11]. Не смотря на разнообразие трактовок понятия «контекст» в междисциплинарном научном дискурсе, в широком смысле контекст (от лат. - contextus- тесная связь, соединение) - это система факторов - время (прошлое, настоящее, будущее), место и реальные события, происходящие в жизни человека и окружающих - все, что помогает понимать и интерпретировать смысл происходящего. Причем, контексты могут быть различными - поведенческими, деятельностными, социальными, эмоциональными, культурными, историческими, образовательными и др. [4]. Реализуя в исследовании психологического благополучия студентов контекстный подход, мы рассматриваем контекст как систему внутренних и внешних условий жизни и деятельности студента, которая влияет на восприятие, понимание и преобразование им конкретной ситуации, придавая смысл и значение этой ситуации, помогает определить место и роль субъекта в данной ситуации. Реализация контекстного подхода выстраивается на принципе расширения, принципе взаимосвязи и вариативности контекста, принципе контекстной обусловленности, принципе системности и дополнительности [2].

Подводя итог, следует отметить, что мы рассматриваем психологическое благополучие студентов как интегральную характеристику состояний субъекта, 
обеспечивающих согласованность всех психических функций и процессов, достижение внутреннего равновесия и субъектной целостности. Субъективное благополучие в нашем понимании является осознаваемой частью психологического благополучия, внутренним образом собственной жизни и своего места в ней.

Методологической основой изучения психологического благополучия студентов, проживающих в России и Армении, в нашем исследовании являются:

- социокультурный подход, рассматривающий развитие студента в контексте его взаимодействия со средой, предполагающий изучение влияния на уровень психологического благополучия ближайшего социального окружения (особенности образовательной среды, семейного климата, социального капитала), а также макро-факторов (этнос, национальные традиции, идеология и ценности, социально-экономический уклад жизни);

- контекстный подход, позволяющий рассматривать ситуацию очного обучения в вузе в качестве значимого фактора психологического благополучия российских и армянских студентов, а также при учете иных контекстов жизни (проживание в семье или отдельно от родителей, проживание в родном городе или переезд в другой город, «академический» вариант обучения или совмещение учебы с работой и др.).

\section{Литература}

1. Берзин Б. Ю. Психологическое благополучие личности: к вопросу о сущности понятия. Известия Уральского федерального университета. Сер. 1, Проблемы образования, науки и культуры. 2018. Т. 24, № 4 (180). c. 74-81.

2. Вербицкий А.А., Калашников В.Г. Контекстный принцип в психологии. Психологический журнал. 2015. Том 36. № 3. с. 5-14.

3. Кислицына О.А. Измерение качества жизни / благополучия: международный опыт. М.: Институт экономики РАН, 2016. 62 с.

4. Крюкова. Т.Л., Гущина Т.В. Культура, стресс и копинг: социокультурная контекстуализация совладающего поведения. Кострома : КГУ им. Н.А. Некрасова; КГТУ, 2015. 236 с.

5. Лапин Н.И. Социокультурный подход и социетально-функциональные структуры. Социологические исследования. 2000. № 7. с. 3-12.

6. Мацумото Д. Психология и культура. СПб: Прайм-Еврознак, 2002. 416 c.

7. Панов В.И. Экологическая психология: Опыт построения методологии, М.:Наука, 2004. 197 с. 
8. Парсонс Т. Понятие культуры и социальной системы // О социальных системах / Под ред. В.Ф. Чесноковой и С.А. Белановского. М.: Академический Проект, 2002. с. 693-776.

9. Пермякова М.Е., Ершова И.А. Субъективное ощущение счастья у верующих и атеистов. Изв. Урал. фед. ун-та. Сер. 1 :Проблемы образования, науки и культуры. 2015. № 3 (141). с. 69-78.

10. Прохоров А.О. Определение понятия «психологическое состояние // Психология состояний: хрестоматия. СПб., 2004. с. 34-39.

11. Самохвалова А.Г. Коммуникативные трудности ребенка в поликультурной социальной среде: монография. Кострома: КГУ, 2019. 280 с.

12. Шевеленкова Т.Д., Фесенко Т.П. Психологическое благополучие личности. Психологическая диагностика. 2005. № 3. с. 95-121.

13. Bronfenbrenner U., Morris P. The ecology of developmental processes / U. Bronfenbrenner, // In W. Damon, R. M. Lerner (Eds.). Handbook of child psychology. NY : John Wiley \& Sons, 1998. pp. 993-1028.

14. Ryff C.D., Keyes C.L.M. (1995). The structure of psychological well-being revisited. Journal of Personality Social Psychology. 69. pp. 719-729.

\section{METHODOLOGICAL APPROACHES TO THE RESEARCH OF PSYCHOLOGICAL WELL-BEING OF RUSSIAN AND ARMENIAN STUDENTS}

Samokhvalova A.G. (Kostroma State University, Kostroma, Russia), Asriyan E.V. (Yerevan State University, Yerevan, Armenia)

The article raises the actual problem of studying the psychological well-being of students. The author's understanding of the "well-being", "psychological wellbeing" and "subjective well-being" of a person is presented. Psychological well-being is defined as an integral characteristic of the subject's states that ensure the consistency of all mental functions and processes, the achievement of internal balance and subjective integrity. Methodological approaches to the organization of a cross-cultural study of the psychological well-being of students enrolled in Russian and Armenian universities have been substantiated. As the most important approaches, the sociocultural approach is defined, which considers the development of a student in the context of his interaction with the environment, involving the study of the impact on the level of psychological well-being of the immediate social environment (especially the educational environment, family climate, social capital), and other macro-factors (ethnicity, national traditions, ideology, values, socioeconomic way of life); as well as a contextual approach that allows us to consider the situation of full-time education at a university as a predictor of the psychological well-being of Russian and Armenian students, taking into account other contexts of 
life (living with a family or apart from parents, living in a hometown or moving to another city, the "academic" option learning or combining study with work).

Keywords: well-being, psychological well-being, subjective well-being, students, sociocultural approach, contextual approach. 